www.jmscr.igmpublication.org

Impact Factor 5.244

Index Copernicus Value: 83.27

ISSN (e)-2347-176x ISSN (p) 2455-0450

crossref DOI:_http://dx.doi.org/10.18535/jmscr/v4i9.45

Journal Of Medical Science And Clinical Research

\title{
Acalculous Cholecystitis as a Presentation of Acute Hepatitis B \\ (Case Report)
}

\author{
Authors \\ Syed Haider Mehdi Husaini ${ }^{1}$, Syed Hasan Amir ${ }^{2}$ \\ ${ }^{1,2}$ Assistant Professor, Dept of Medicine Jawaharlal, Nehru Medical College, A.MU., Aligarh.,U.P., India \\ Corresponding Author \\ Syed Hasan Amir \\ Dept of Medicine, J.N.Medical College, A.M.U, Aligarh, India \\ Email: hasanamir77@gmail.com, Mobile No: +918979295129
}

\begin{abstract}
Acalculous cholecystitis (ACC) as commonly understood, is an inflammation of the gall bladder in the absence of stones. Acute viral hepatitis B though being a systemic infection, predominantly affects the liver but also produces changes in the function, as well as anatomy of the gall bladder. Acute viral hepatitis $B$ presenting as ACC is not common and has been reported only in a few cases. We here report case of a $40 y r$ old female patient who presented with ACC associated with jaundice and was later diagnosed to have acute hepatitis $B$. She was placed on conservative treatment only and recovered completely in a week's time.

Keywords: Acalculous cholecystitis, acute hepatitis B.
\end{abstract}

\section{INTRODUCTION}

Acute viral hepatitis B usually presents as jaundice, fever, malaise, hepatomegaly, nausea and vomiting but acalculous cholecystitis is a very uncommon presentation at the onset. Case reports on linking ACC with viral hepatitis are also few.

We report an unusual case of acute hepatitis presenting as acalculous cholecystitis; eventually, there was a complete recovery. The rarity of the clinical presentation and its favourable outcome is the reason for its reporting.

\section{CASE REPORT}

A $40 \mathrm{yr}$ old female patient presented to the emergency ward with complaints of progressive jaundice for the past 20 days and moderate to severe abdominal pain for 6hrs. The abdominal pain was insidious in onset, moderate to severe in intensity, described as heaviness, located in the epigastrium, non radiating with no improvement or aggravation on assuming anybody posture. There were associated complaints of yellowish discolouration of urine, fever, malaise, body ache, severe nausea and several episodes of vomiting. There was no history of altered sleep patterns, inebriation, loss of consciousness or bleeding from any site, pruritis, prior blood transfusions, surgery or dental extractions, no family member had chronic hepatitis On examination, the general condition of the patient was stable, mild pallor was seen, icterus was found in the sclera, liver was palpable two fingers below the costal margin, 
tenderness elicited in the right hypochondrium and epigastrium. Murphy's sign was positive.

Her hemogram revealed $\mathrm{Hb} 9.8 \mathrm{~g} / \mathrm{dl}$, TLC 6,300/mcl, DLC P55 L36 E08 B0, Liver Function test (LFT) showed Total Bilirubin(T BIL) $17.3 \mathrm{mg} / \mathrm{dl}$ Direct Bilirubin (D BIL) $12.7 \mathrm{mg} / \mathrm{dl}$ Alanine Transaminase (ALT) 1241 IU/L (Normal=30-65IU/L) Aspartate Transaminase (AST) 1100 IU/L(Normal=15-37IU/L) Alkaline phosphatase $228 \mathrm{mc} / \mathrm{l}$, Total Serum Protein(TSP) 6.4g, Serum Albumin (ALB) 3.5, Globulin (GLOB) 3.1, A:G ratio 1.1:1.0, Prothrombin Time (PT) 15.4, International Normalized Ratio(INR) 1.3. She was Australia antigen(HBsAg) positive and IgM Anti Hbc positive. Renal function test, serum amylase and lipase, chest x-ray and ECG were within normal limits. Her abdominal ultrasound (USG) showed diffuse gall bladder wall edema (thickness of $12 \mathrm{~mm}$ ) with mild pericholecystic fluid. There were no gallstones and CBD was undilated as shown in figure1.

Malaria parasite smear was negative, blood culture sterile, Widal negative, urine pregnancy test negative, Anti HCV negative, HIV negative.

The patient was treated with intravenous fluid, parenteral pantoprazole, metoclopramide and antispasmodics. On improvement, she was placed on high carbohydrate diet with moderate fat restriction.

On follow up, the patient's nausea, vomiting, malaise and abdominal pain had subsided and she was on oral therapy. Her LFT showed TBIL $13.5 \mathrm{mg} / \mathrm{dl}$ DBIL $11.8 \mathrm{mg} / \mathrm{dl}$ ALT 136 IU/L (Normal=30-65IU/L) AST 105 IU/L(Normal=1537IU/L) ALP 12mc/l, PT 11.4 INR 1.0. HBV DNA level was in lower limit of detection. Her USG abdomen on day 7 showed a normal gall bladder ( $3 \mathrm{~mm}$ wall thickness) with no stones or fluid collection.

The patient was then discharged in good medical condition and was advised to review in our Out Patient Department.

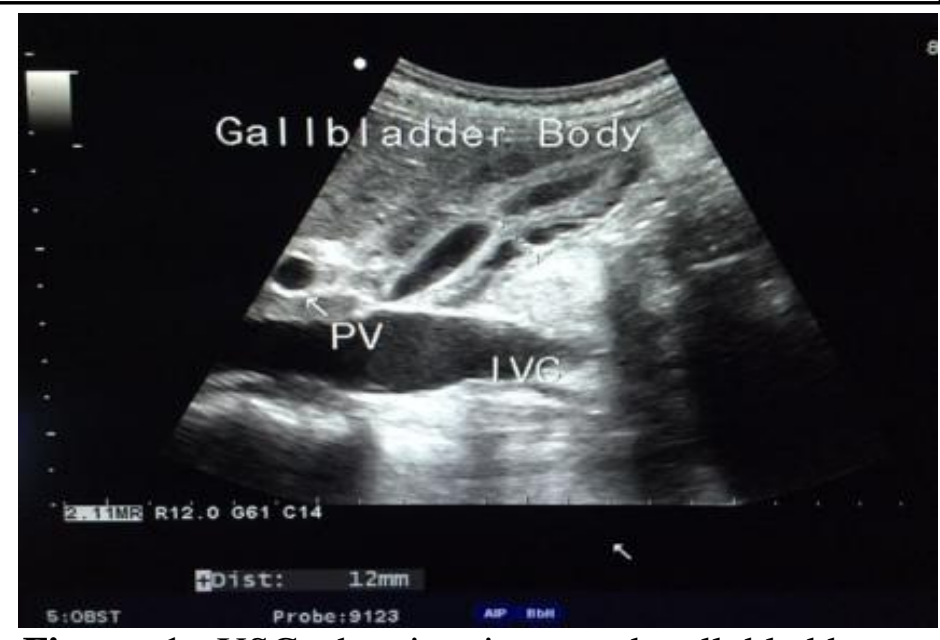

Figure 1: USG showing increased gall bladder thickness $(12 \mathrm{cms})$ with pericholecystic fluid collection

\section{DISCUSSION}

Acalculous cholecystitis is described as an inflammation of the gall bladder in the absence of stones or cystic duct obstruction. Ultrasound proved changes do occur in the gall bladder in adults having acute viral hepatitis in $50-100 \%$ of cases. Gall bladder collapse and gall bladder wall thickening being the most common findings. ${ }^{[1-5]}$ Ultrasonography has a sensitivity and specificity of $92 \%$ and $96 \%$ respectively in diagnosing ACC. Diagnosis of ACC on ultrasonography requires 2 major or 1 major and 1 minor criteria to be met. The major criteria include gall bladder wall thickening (> 3mm), GB wall edema, ultrasonographic Murphy's sign, pericholecystic fluid, mucosal sloughing, intramural gas while the minor criteria comprises sludge and GB distension (>5cm transverse). ${ }^{[6]}$ As our patient fulfilled two major criteria which were gall bladder wall thickening of $12 \mathrm{~mm}$, a positive Murphy's sign and absence of stones or cystic duct obstruction associated with jaundice and right hypochondrial pain; it can be safely concluded that she was suffering from ACC.

Our patient also suffered from highly raised ALT, AST and serum bilirubin levels along with raised PT and INR suggesting acute hepatitis. Along with this, she was HBsAg and IgM Anti Hbc positive confirming the diagnosis of acute viral hepatitis B. 
There are very few case reports on the association of ACC with acute viral hepatitis B. ${ }^{[7,8]}$ As in our case also, both these reported cases describe an otherwise healthy ambulatory adult patient getting infected with acute hepatitis B and presenting with ACC bearing a self limiting course. This is unlike classical ACC which commonly affects chronic hospitalized and debilitated patients having a high complication rate and a mortality ranging from $10-50 \%$ as compared with a $1 \%$ mortality rate of calculus cholecystitis. A proposal of empirical cholecystectomy is also being considered in view of the high mortality rate. ${ }^{[9]}$ Our patient on the other hand was kept on conservative therapy only and she improved without having any complications.

A number of reasons have been given explaining the pathogenesis of ACC in acute viral hepatitis. The viral infection causes inappropriate activation of factor XII leading to inflammation of the gall bladder wall (as demonstrated in animals) and a local release of prostaglandins also causing gall bladder wall thickening. ${ }^{[10,11]}$ Such inflammation may involve the micro circulation of the gall bladder wall leading to ischemic damage also. ${ }^{[12]}$ Secondly, acute viral hepatitis is also characterized by profound necrosis of hepatocytes due to inflammation which also encompasses surrounding structures such as the gall bladder wall. ${ }^{[13]}$ Thirdly, the hepatitis virus in the bile might also infect the gall bladder wall directly leading to inflammation of its muscle tissue. ${ }^{[14]}$

In conclusion, it is certain that acute viral hepatitis B may involve the gall bladder wall leading to ACC even though it is very rare. The patients are previously healthy and active. The morbidity and mortality is very low. The illness is self limiting and the management is conservative. This is in sharp contrast to classical cases of ACC where debilitated and bed bound patients are affected with high complication rates and mortality. Cholecystostomy or cholecystectomy is preferred. Our suggestion is that more such cases need to be reported, followed up and studied; so that a comprehensive policy towards the diagnosis and management of such cases may be formulated. This would save those patients having ACC from viral hepatitis from unnecessary early surgical intervention.

\section{SOURCE OF SUPPORT: Nil}

\section{REFERENCES}

1. Maresca G, De Gaetano AM, Mirk P, et al. Sonographic patterns of the gallbladder in acute viral hepatitis. J Clin Ultrasound. 1984; 12: 141-6.

2. Sharma MP, Dasarathy S. Gallbladder abnormalities in acute viral hepatitis: a prospective ultrasound evaluation. J Clin Gastroenterol. 1991; 13: 697-700.

3. Giorgio A, Francica G, Amoroso P, et al. Morphologic and motility changes of the gallbladder in response to acute liver injury. A prospective real-time sonographic study in 255 patients with acute viral hepatitis. J Ultrasound Med. 1989; 8(9): 499-506.

4. Portincasa P, Moschetta A, Di Ciaula A, et al. Changes of gallbladder and gastric dynamics in patientsmwith acute hepatitis. Eur J Clin Invest. 2001; 31: 617-22.

5. Zivković R, Trajer A. Ultrasound diagnosis of acute viral hepatitis. Acta Med Croatica. 1998; 52: 109-13.

6. Mirvis SE, Vainright JR, Nelson AW, et al. The diagnosis of acute acalculous cholecystitis: a comparison of sonography, scintigraphy, and CT. AJR Am J Roentgenol. 1986; 147: 1171-5.

7. Unal H, Korkmaz M, Kirbas I, Selcuk H, Yilmaz U. ACC associated with acute viral hepatitis B infection. Int J Infect Dis. 2009 ;13:310-2.

8. Riyadh Ali Muhammad, Wisam Ghadban, Osama Muhammad.ACC induced by acute viral hepatitis B.Case Reports in Hepatology Volume 2012 (2012), Article ID 132345, 4 pages. 
9. Edge SB, Byrd DR, Compton CC, et al. AJCC cancer staging manual. New York: Springer; 2009.

10. Zepeda-Gomez S, Baron TH. Benign biliary strictures: Current endoscopic management. Nat Rev Gastroenterol Hepatol 2011; 8:573-81

11. Choudhary A, Bechtold ML, Arif M, et al.Pancreatic stents for prophylaxis against post ERCP pancreatitis: A meta-analysis and systemic review. Gastrointest Endosc 2011; 73:275-82.

12. Glenn F, Becker CG. Acute acalculous cholecystitis. An increasing entity. Ann Surg. 1982; 195: 131-136.

13. Juttner HU, Ralls PW, Quinn MF, et al. Thickening of the gallbladder wall in acute hepatitis: ultrasound demonstration. Radiology. 1982; 142: 465.

14. Dogra R, Singh J, Sharma MP. Enterically transmitted non-A, non-B hepatitis mimicking acute cholecystitis. Am J Gastroenterol. 1995; 90: 764. 